\title{
Research Letter \\ Determination of Differential Enthalpy and Isotherm by Adsorption Calorimetry
}

\author{
V. Garcia-Cuello, ${ }^{1}$ J. C. Moreno-Piraján, ${ }^{1}$ L. Giraldo-Gutiérrez, ${ }^{2}$ K. Sapag, ${ }^{3}$ and G. Zgrablich ${ }^{3,4}$ \\ ${ }^{1}$ Research Group on Porous Solid and Calorimetry, Department of Chemistry, Faculty of Sciences, \\ University of the Andes, Carrera 1 No. 18 A 10 Bogotá, Colombia \\ ${ }^{2}$ Department of Chemistry, Faculty of Sciences, National University of Colombia, Ciudad Universitaria, \\ Transversal 38 No. 40-01 Bogotá, Colombia \\ ${ }^{3}$ Instituto de Física Aplicada (INFAP), CONICET-Universidad Nacional de San Luis, Ejército de los Andes 950, \\ San Luis D5700HHW, Argentina \\ ${ }^{4}$ Departamento de Engenharia Química, Universidade Federal do Ceará, Campus do Pici, \\ Fortaleza 60455-760, Brazil
}

Correspondence should be addressed to J. C. Moreno-Piraján, jumoreno@uniandes.edu.co

Received 15 May 2008; Accepted 23 June 2008

Recommended by Anatoly Rusanov

\begin{abstract}
An adsorption microcalorimeter for the simultaneous determination of the differential heat of adsorption and the adsorption isotherm for gas-solid systems are designed, built, and tested. For this purpose, a Calvet heat-conducting microcalorimeter is developed and is connected to a gas volumetric unit built in stainless steel to record adsorption isotherms. The microcalorimeter is electrically calibrated to establish its sensitivity and reproducibility, obtaining $K=154.34 \pm 0.23 \mathrm{WV}^{-1}$. The adsorption microcalorimeter is used to obtain adsorption isotherms and the corresponding differential heats for the adsorption of $\mathrm{CO}_{2}$ on a reference solid, such as a NaZSM-5 type zeolite. Results for the behavior of this system are compared with those obtained with commercial equipment and with other studies in the literature.
\end{abstract}

Copyright (c) 2008 V. Garcia-Cuello et al. This is an open access article distributed under the Creative Commons Attribution License, which permits unrestricted use, distribution, and reproduction in any medium, provided the original work is properly cited.

\section{INTRODUCTION}

It is widely accepted that the knowledge of adsorption heats is vital in the description of gas-solid interaction. This is particularly useful when adsorption heat measurements are combined with simultaneous measurement of the adsorption isotherm. These measurements obviously may provide information about the energetic of surface processes. In some simple cases, even information on the structure of the surface itself, like for example the energetic topography, can be retrieved from adsorption heats and isotherms $[1,2]$. Chemisorption and catalyzed reactions, like any chemical reaction, are associated with changes of enthalpy and can therefore be studied by means of calorimeters. Many calorimeters, operating on different principles, have indeed been used for this purpose [3-5]. Adsorption calorimeters are particularly convenient for these studies [4]. They offer a number of advantages which will be illustrated by means of selected examples.

Adsorption calorimetry, preferably in association with other physicochemical or physical techniques, may be used to describe the surface properties of a solid.

Information on the binding energy, deduced from calorimetric data, is needed to achieve a theoretical description of the adsorbate-adsorbent bond. It has been shown, for instance, that, in the case of the adsorption of hydrogen on nickel-copper alloys, a correlation between heats of adsorption and surface magnetic properties can be found. The correlation indicates that the energy of the bond between adsorbed hydrogen and nickel atoms is regulated by the electron density of states, near the Fermi level, for the metal surface [6-8].

In these works, we present the design, construction, and test of an adsorption microcalorimeter capable of measuring simultaneously adsorption isotherms and heats. 


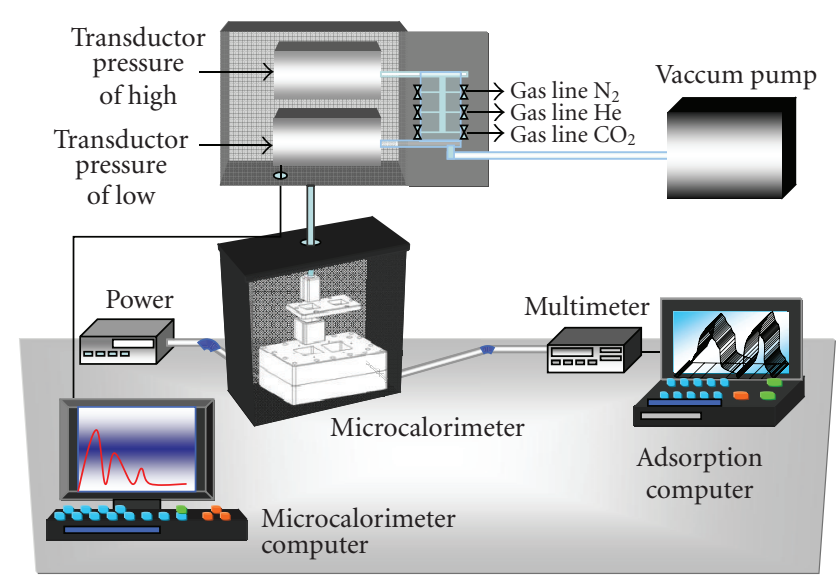

FIGURE 1: General scheme of station for the simultaneous measurement of isotherm and heat of adsorption.

\section{EXPERIMENTAL}

\subsection{Description of the new microcalorimeter}

Figure 1 shows a complete view of the adsorption calorimeter built here, which is not very common and has not been considered in the literature.

A detailed general view of the equipment calorimeter is shown in Figure 1. The diagram shows microcalorimeter with the calorimetric cells made of stainless steel (sample and reference), which are embedded inside a large block (also divided in two parts) in stainless steel, which acts as deposit of the thermostatic liquid. Due to its thermal diffusion coefficient, this set allows the rapid heat conduction towards the surrounding of the calorimeter. The whole set is placed inside a nylon block to isolate it from the surroundings and to allow the rapid stabilization of the temperature. The thermal effects are sensed through ten thermopiles and trademark Melcor Corporation, NJ, USA, connected in series to increase the sensitivity of the microcalorimeter. The microcalorimeter designed in this work connected to the adsorption system constructed specially for this equipment in stainless steel to allow the simultaneous measurement of the heat of adsorption and the isotherm. The connection is through two pressure transducers, one in the range of high pressure (1000 Torr), and the other in the range of low pressure (10 Torr) (see Figure 1).

\subsection{Electric calibration of the adsorption microcalorimeter}

In order to establish the correct functioning of the microcalorimeter, which is then connected to the volumetric adsorption unit, the sensitivity is evaluated determining the calorimeter constant. The calibration constant reports the voltage generated by the calorimeter when a heat flow is emitted from inside the microcalorimetric cell. There are two methods to determine the calibration constant $K$ : by application of electric power and by the stationary method $[9,10]$.
TABLE 1: Comparison of principal superficial characteristics of NaZSM-5 zeolite.

\begin{tabular}{lcc}
\hline $\begin{array}{l}\text { NaZSM-5 } \\
\text { ZEOLITE }\end{array}$ & Quantachrome $3 \mathrm{~B}^{\mathrm{TM}}$ & $\begin{array}{l}\text { Microcalorimeter } \\
\text { built in this work }\end{array}$ \\
\hline $\begin{array}{l}S_{\mu p} \text {-DRK-method } \\
\left(\mathrm{m}^{2} / \mathrm{g}\right)\end{array}$ & 285 & 296 \\
$\begin{array}{l}V_{\mu p} \text {-DRK-method } \\
\left(\mathrm{cm}^{3} / \mathrm{g}\right)\end{array}$ & 0.24 & 0.26 \\
\hline
\end{tabular}

\subsection{Description of the unit for simultaneous measurement of isotherm and adsorption heat}

Heats of adsorption have been measured at $273 \mathrm{~K}$ by means of the adsorption microcalorimeter and by contacting the solid with small successive doses of the adsorptive. This allows the evolution of the interaction energy along with the coverage to be measured. In the system, an ultrahigh vacuum pump (Pfeiffer Vacuum Ref. TSH 071E) is previously connected to an oil rotary pump which initially allows to have a previous vacuum in all the system. Once the system has a pressure of about $10^{-3}$ Torr, the ultra-high vacuum pump starts working and is kept functioning until the pressure reaches at least $10^{-5}$ Torr. This part of the station is also composed of a joint built all in one unit, all in stainless steel, which was previously calibrated and was specially designed to obtain precise and accurate measurements. This is a novel contribution to the research equipments normally used in this type of measurements where this part consists of equipment constructed in glass with the problems associated with it. The cell containing the sample is also shown as well as the pirani pressure transductor which is connected to a computer through an interface RS-232.

The differential heat of adsorption is obtained directly from the calorimetric, measuring the heat evolved, as small increments of adsorbate are added. This method is the one used in this work.

\section{RESULTS}

\subsection{Electric calibration of the adsorption microcalorimeter}

The calibration constants were obtained for the operation conditions of the microcalorimeter. Constants between range $134.11 \pm 0.19 \mathrm{WV}^{-1}$ to $156.67 \pm 0.23 \mathrm{WV}^{-1}$ are determined. These values show the sensitivity of the microcalorimeter built here, which is higher than that of equipments reported in literature and even of those built in our laboratory previously. This constitutes a significant contribution to the construction of this type of instruments. Values by the method of state stationary condition were obtained and were of the order same and magnitude.

\subsection{Isotherms and differential heats of adsorption}

Table 1 reports the characterization results obtained with the equipment built here for the probe sample, type NaZSM-5 zeolite, previously characterized in an Autosorb 


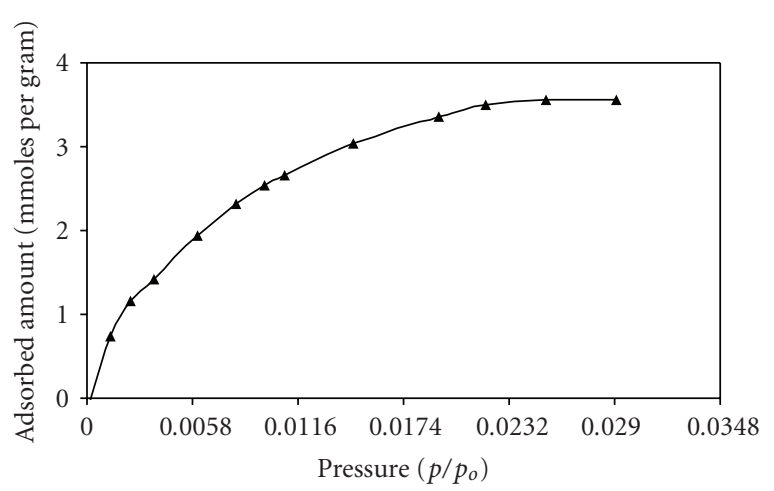

Figure 2: Adsorption isotherm for zeolite in $\mathrm{CO}_{2}$ at $273 \mathrm{~K}$.

Quantachrome 3B equipment. The superficial characteristics and microporosities obtained with the two equipments are compared.

These values are evaluated from the adsorption of $\mathrm{CO}_{2}$ at $298 \mathrm{~K}$. The results show a very good agreement between the commercial equipment and the microcalorimeter built here, reinforcing the excellent functioning of this equipment. Figure 2 shows the adsorption isotherm of $\mathrm{CO}_{2}$ at $273 \mathrm{~K}$ obtained for the zeolite analyzed in this investigation. This isotherm was reproduced also on the commercial equipment with a good concordance, reinforcing again the satisfactory behavior of our apparatus.

It is interesting to analyze jointly the data obtained from the adsorption isotherm (see Figure 2) and those for the differential heat of adsorption (see Figure 3 ). In $\mathrm{Na}$ exchanged ZSM-5 zeolites, Na cations neutralize the acidity of the zeolite and develop the basicity for adsorbing acidic $\mathrm{CO}_{2}$. Thus, NaZSM-5 provides two kinds of adsorption sites for $\mathrm{CO}_{2}$ : stronger sites around a $\mathrm{Na}$ cation (which saturates rapidly) and weaker sites on the pore walls [11]. The steep increase of the adsorption isotherm and the high value of $q_{d}$ at low pressure $\left(p / p_{o}<0.01\right)$ in Figures 2 and 3 reveal in a clear way the presence of these strong sites, which become rapidly saturated. Note also that the steep decrease in $q_{d}$ at very low pressure from 48 to $46 \mathrm{~kJ} / \mathrm{mol}$ is indicating that the adsorption strength of these sites is not uniform (indication of energetic heterogeneity). After the strong sites become saturated $\left(p / p_{o}>0.01\right), q_{d}$ steps down to a lower and almost constant value, corresponding to adsorption on the zeolite walls, and simultaneously the amount adsorbed increases more slowly in the isotherm. This is in [11] and shows the potentiality of the microcalorimetric station.

\section{CONCLUSIONS}

A modern adsorption microcalorimeter was built for the simultaneous measurement of isotherms and adsorption heats, establishing its correct functioning through adequate calibration of both the calorimeter part and the volumetric equipment of the adsorption part. For this purpose, the microcalorimeter calibration constant was found with values that go from $134.11 \pm 0.19 \mathrm{WV}^{-1}$ to $156.67 \pm 0.23 \mathrm{WV}^{-1}$. The adsorption isotherm was determined for a type NAZSM-5

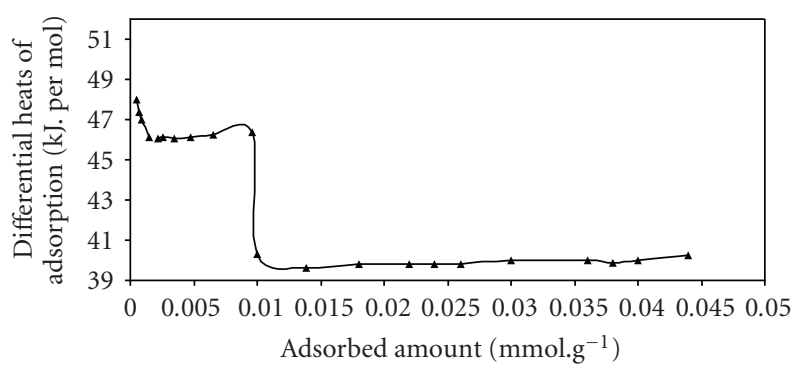

Figure 3: Differential heats of adsorption for $\mathrm{CO}_{2}$ on NAZSM-5 zeolite.

zeolite as a reference solid to establish the correct functioning of the equipment. Micropore volume and superficial area were determined to be $0.20 \mathrm{~cm}^{3} / \mathrm{g}$ and $296 \mathrm{~m}^{2} / \mathrm{g}$, respectively. These results agree very well with those obtained with commercial equipment. Finally, the differential heats of adsorption, for the same solid, were measured. The analysis of results gives valuable information about the studied $\mathrm{CO}_{2} / \mathrm{NaZSM}-5$ system, which is in concordance with other studies in the literature.

\section{ACKNOWLEDGMENTS}

The authors thank the Departments of Chemistry of National University of Colombia, University of the Andes (Colombia), and Universidad Nacional de San Luis (Argentina), and the Master Agreement established between these institutions. Special gratitude is due to Fondo Especial de Investigaciones de la Facultad de Ciencias de la Universidad de Los Andes (Colombia) for its partial financing. Dr. Diana Azevedo is also kindly acknowledged for profiting discussions on the characteristics of the $\mathrm{CO}_{2} / \mathrm{NaZSM}-5$ system. One of the authors, G. Zgrablich, thanks CAPES (Brazil) for a Visiting Professor Fellowship at UFC.

\section{REFERENCES}

[1] W. Rudzinski, W. A. Steele, and G. Zgrablich, Eds., Equilibria and Dynamics of Gas Adsorption on Heterogeneous Solid Surfaces, Elsevier, Amsterdam, The Netherlands, 1997.

[2] F. Bulnes, A. J. Ramirez-Pastor, and G. Zgrablich, "Scaling behavior of adsorption on patchwise bivariate surfaces revisited," Langmuir, vol. 23, no. 3, pp. 1264-1269, 2007.

[3] P. C. Gravelle, "Calorimetry in adsorption and heterogeneous catalysis studies," Catalysis Reviews, vol. 16, no. 1, pp. 37-110, 1977.

[4] P. C. Gravelle, "Heat-flow microcalorimetry and its application to heterogeneous catalysis," Advances in Catalysis, vol. 22, pp. 191-263, 1972.

[5] A. Auroux, J. C. Vedrine, and P. C. Gravelle, in Adsorption at the Gas-Solid and Liquid-Solid Interface, J. Rouquerol and K.S.W. Sing (Eds), pp. 305-322, Elsevier, Amsterdam, The Netherlands, 1982.

[6] J. J. Prinsloo and P. C. Gravelle, "Volumetric and calorimetric study of the adsorption of hydrogen, at $296 \mathrm{~K}$, on silicasupported nickel and nickel-copper catalysts," Journal of the Chemical Society, Faraday Transactions 1, vol. 76, pp. 22212228, 1980. 
[7] A. Auroux and P. C. Gravelle, "Comparative study of the bond energy of oxygen at the surface of supported silver catalysts and of the activity of these catalysis for ethylene epoxidation," Thermochimica Acta, vol. 47, no. 3, pp. 333-341, 1981.

[8] P. C. Gravelle and S. J. Teichner, "Carbon monoxide oxidation and related reactions on a highly divided nickel oxide," Advances in Catalysis, vol. 20, pp. 167-266, 1969.

[9] J. C. Moreno, Diseño, construcción, calibración y aplicación de un Microcalorímetro de conducción de calor, Ph.D. Thesis, National University of Colombia, Bogotá, Colombia, 1996.

[10] L. Giraldo, Diseño de un Microcalorímetro de flujo tipo gemelo y su aplicación el estudio de las interacciones alcoholes en solución acuosa, Ph.D. Thesis, National University of Colombia, Bogotá, Colombia, 1996.

[11] S. K. Wirawan and D. Creaser, " $\mathrm{CO}_{2}$ adsorption on silicalite1 and cation exchanged ZSM-5 zeolites using a step change response method," Microporous and Mesoporous Materials, vol. 91, no. 1-3, pp. 196-205, 2006. 


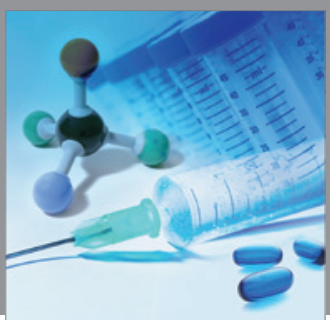

International Journal of

Medicinal Chemistry

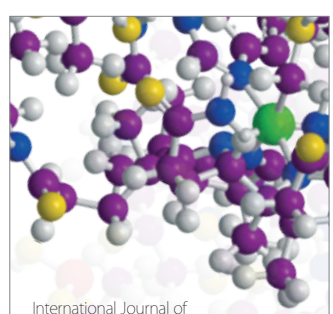

Carbohydrate Chemistry

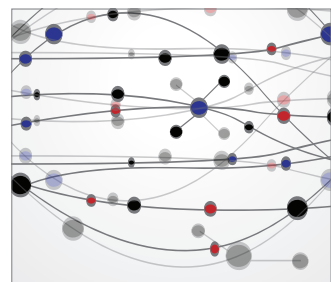

The Scientific World Journal
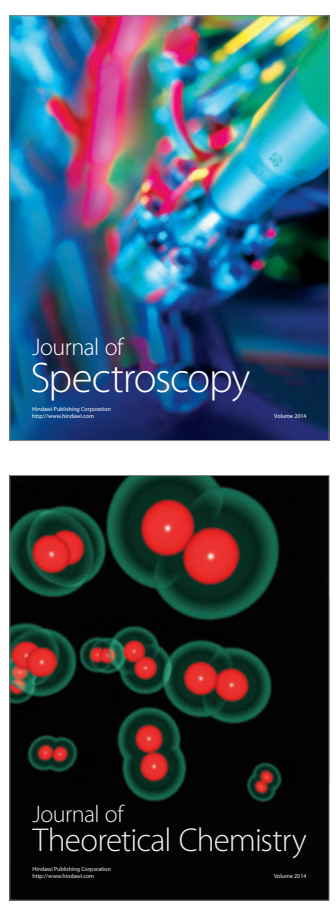
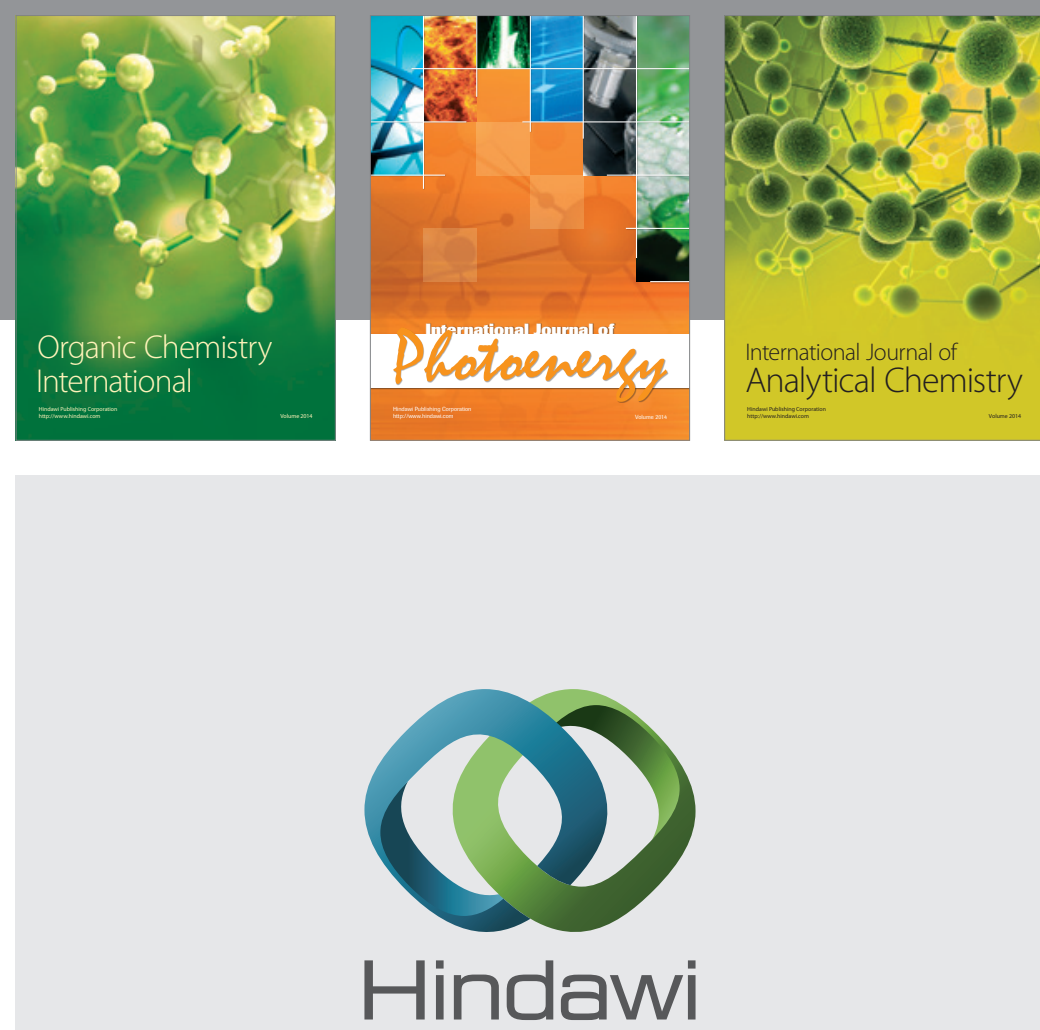

Submit your manuscripts at

http://www.hindawi.com
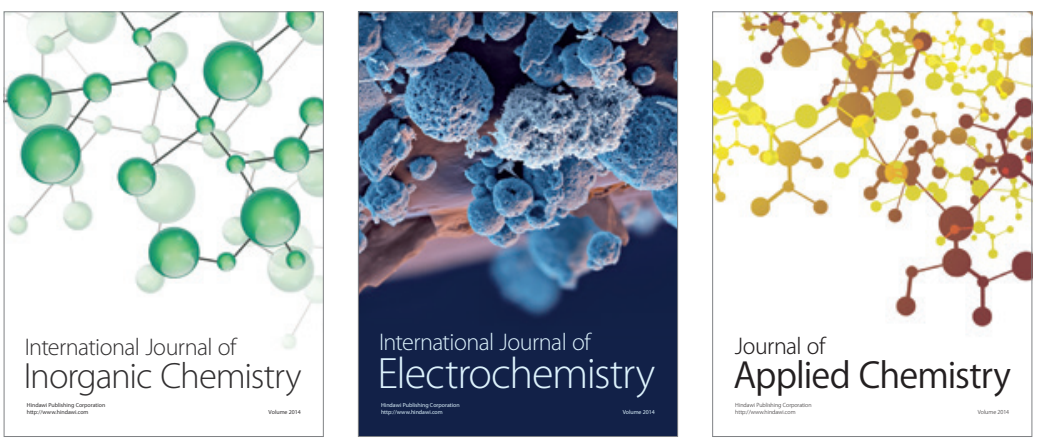

Journal of

Applied Chemistry
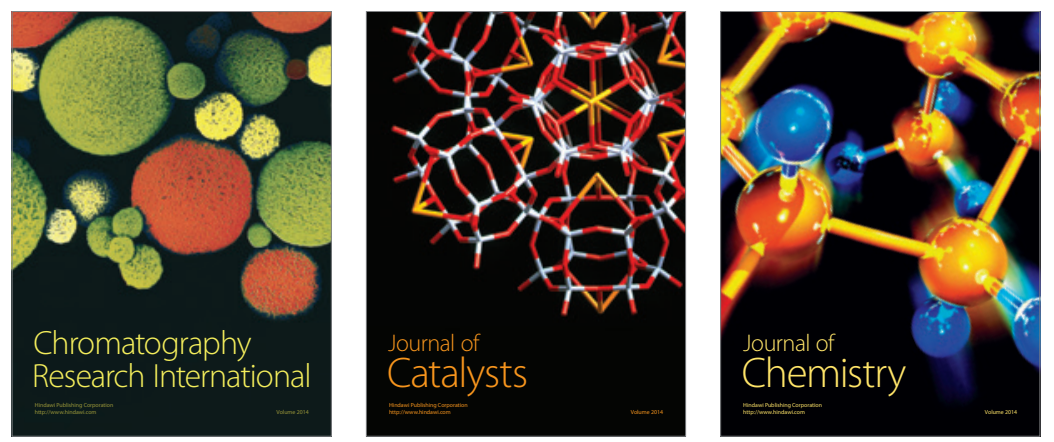
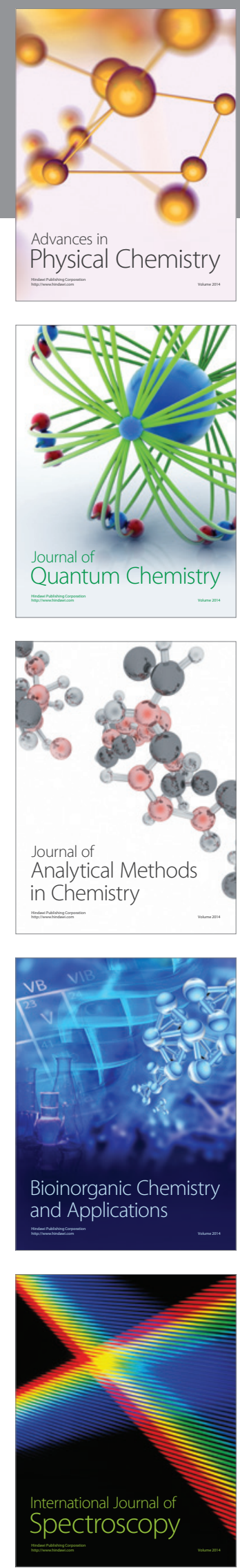